\title{
Exercise-induced arterial hypoxemia in aerobic and anaerobic trained athletes during incremental exercise
}

\author{
Selcen Korkmaz Eryılmaz ${ }^{1 \mathrm{ABCD}}$, Metin Polat ${ }^{2 \mathrm{ABC}}$ \\ ${ }^{1}$ School of Physical Education and Sports, Cukurova University, Adana, Turkey \\ ${ }^{2}$ School of Physical Education and Sports, Erciyes University, Kayseri, Turkey
}

Authors' Contribution: A - Study design; B - Data collection; C - Statistical analysis; D - Manuscript Preparation; E - Funds Collection.

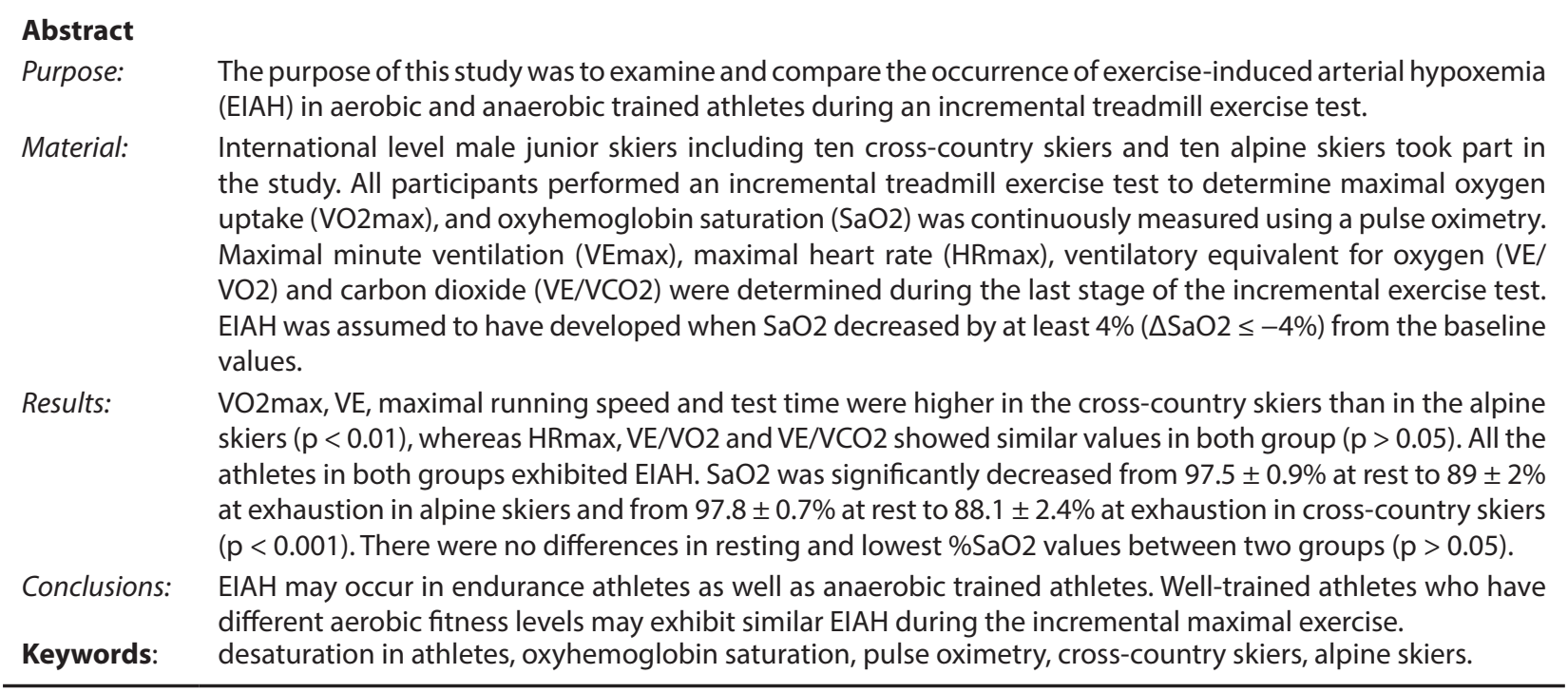

\section{Introduction}

Earlier studies found that many healthy athletes experience exercise induced arterial hypoxemia in a normoxic environment [1]. This finding is indicating that the lungs may be a limiting factor [2]. Exerciseinduced arterial hypoxemia (EIAH) is known to occur in be approximately $50 \%$ of endurance athletes and developed especially at high exercise intensities [24]. EIAH is manifested as a reduced partial pressure of arterial oxygen $\left(\mathrm{PaO}_{2}\right)$ or as a reduced saturation of hemoglobin in some athletes [2]. $\mathrm{PaO}_{2}$ is reduced below resting levels due to an excessive widening of the alveolar to arterial oxygen difference. A diffusion limitation and inadequately hyperventilation have been cited as the cause of the excessively widened arterial oxygen difference during exhaustive exercise [2, 5]. Reductions in arterial oxyhemoglobin saturation $\left(\mathrm{SaO}_{2}\right)$ below resting levels are usually due to a combination of a reduction in $\mathrm{PaO}_{2}$, metabolic acidosis and increasing body temperature induced shifts to the right in oxygen-haemoglobin dissociation curve $[2,5]$.

$\mathrm{SaO}_{2}$, which depends mainly on gas exchange and characterized by the oxygen-hemoglobin dissociation curve, is a determinant of the oxygen supply to contracting skeletal muscle. Decreases in arterial content of oxygen result in decreases in $\mathrm{SaO}_{2}$ and, subsequently, systemic oxygen transport and maximal oxygen uptake are negatively affected [6]. EIAH contributes to local muscle

(c) Selcen Korkmaz Eryılmaz, Metin Polat, 2018 doi:10.15561/20755279.2018.0207 fatigue [7]. Development of EIAH has been observed to be more common among athletes with high maximal oxygen uptake $\left(\mathrm{VO}_{2 \max }>60 \mathrm{ml} / \mathrm{kg} / \mathrm{min}\right)[2-4,6,8]$. It has been shown that preventing reductions in $\mathrm{SaO}_{2}$ via a small increase in the fraction of inspired oxygen $\left(\mathrm{FIO}_{2}\right)$ increased $\mathrm{VO}_{2 \max }$ and exercise time to exhaustion in most subjects $[6,9]$.

EIAH defined as a decrease in $\mathrm{SaO}_{2}$ of greater than $4 \%$ from rest [2]. On the other hand, EIAH can be classified as mild (93-95\% $\left.\mathrm{SaO}_{2}\right)$, moderate $\left(88-93 \% \mathrm{SaO}_{2}\right)$, and severe $\left(<88 \% \mathrm{SaO}_{2}\right)$ [2]. The mechanism underlying of EIAH are still unclear. Several mechanisms have been proposed to explain the phenomenon of EIAH, including inadequate alveolar hyperventilation related to training adaptation, ventilation-perfusion mismatch (VA/Q), oxygen diffusion limitation based on low pulmonary capillary blood transit time or interstitial edema and intraand extra-pulmonary shunts or an interaction among these factors [2, 10, 11].

Previous research using pulse oximetry indicated that EIAH is more common in aerobic trained individuals and not appear in untrained healthy males [3, 4, 12]. Studies examining EIAH have primarily focused on aerobic trained individuals [4, 8, 12-18]. Interestingly, no studies have examined the EIAH in anaerobic trained athletes. The purpose of this study was to examine and compare the occurrence of exercise-induced arterial hypoxemia in aerobic and anaerobic trained athletes during an incremental treadmill exercise test. 


\section{Material and methods}

Participants

International level twenty-two male junior skiers including ten cross-country skiers (mean $\pm \mathrm{SD}$; age 17.2 \pm 1.7 years, height $170.2 \pm 5.2 \mathrm{~cm}$, weight $60 \pm 6.9 \mathrm{~kg}$ ) and ten alpine skiers (mean $\pm \mathrm{SD}$; age $17.2 \pm 2.2$ years, height $175.6 \pm 3.7 \mathrm{~cm}$, weight $67.3 \pm 9.1 \mathrm{~kg}$ ) from the Turkey national team took part in the study. Erciyes University Medical Faculty Ethics Committee approved the study (217/554). All testing procedures were fully explained, and written informed consent was obtained for each subject. All measurements took place at the High Altitude and Sports Science Research and Implementation Center at Erciyes University.

\section{Incremental exercise test}

Incremental exercise test was performed on a motorized treadmill (h/p/Cosmos Quasar med, Nussdorf-Traunstein, Germany). Oxygen uptake $\left(\mathrm{VO}_{2}\right)$, carbon dioxide output $\left(\mathrm{VCO}_{2}\right)$ and minute ventilation (VE) were measured online using a breath-by-breath cardiopulmonary exercise testing system (Quark PFT Ergo, Cosmed Srl, Rome, Italy). Before each test, ambient conditions were measured and the gas analyzers and turbine flowmeter were calibrated with known certified gas concentrations $\left(16 \% \mathrm{O}_{2}, 5 \% \mathrm{CO}_{2}\right.$, and balance $\left.\mathrm{N}_{2}\right)$ and a $3 \mathrm{~L}$ calibration syringe, respectively, following the manufacturer's instructions. During the incremental testing period, heart rate (HR) was monitored continuously using a wireless HR monitor (S610i, Polar, Finland) and was synchronized to ventilatory signals. Breath-by-breath data was smoothed using a five-step average filter and then reduced to $15 \mathrm{~s}$ stationary averages.

To make sure the athletes were properly warmed up, prepared, and accustomed to the treadmill, each athletes had to warm up for 6 min at their own pace. Then the athletes were allowed to stop and stretch for about $3 \mathrm{~min}$. Following the warm-up, athletes started running at $7 \mathrm{~km} / \mathrm{h}$ with speed increments of $1 \mathrm{~km} / \mathrm{h}$ (at constant $5 \%$ incline) every minute until they could no longer keep pace. The athletes were instructed to run until voluntary exhaustion, and given strong verbal encouragement throughout the test to elicit their best performance.

The $\mathrm{VO}_{2 \max }$ was defined as the highest $15 \mathrm{~s} \mathrm{VO}_{2}$ value reached during the incremental test. Achievement of VO2max was considered as the attainment of at least two of the following criteria: 1) a plateau in $\mathrm{VO}_{2}$ despite increasing speed, 2) a respiratory exchange ratio $\left(\mathrm{VCO}_{2} /\right.$ $\mathrm{VO}_{2}$ ) above 1.10 , and 3) a HR within 10 beats per minute of age-predicted maximum HR (220 - age). The $\mathrm{VO}_{2 \max }$ value was expressed as a relative value (milliliters per minute per body mass; $\mathrm{ml} \mathrm{kg}^{-1} \mathrm{~min}^{-1}$ ). Test time was recorded as the time from the start of the run until the point of exhaustion. Ventilatory equivalent for $\mathrm{O}_{2}(\mathrm{VE} /$ $\left.\mathrm{VO}_{2}\right)$ and $\mathrm{CO}_{2}\left(\mathrm{VE} / \mathrm{VCO}_{2}\right)$, maximal minute ventilation $\left(\mathrm{VE}_{\max }\right)$ and maximal respiratory exchange ratio $\left(\mathrm{RER}_{\max }\right)$ were express as the highest $15 \mathrm{~s}$ average value obtained during the last stage of the incremental exercise test.

$\mathrm{SaO}_{2}$ was assessed continuously and recorded every 15 $\mathrm{s}$ during the incremental exercise test, using a finger pulse oximeter (Spiropalm 6MWT; COSMED, Rome, Italy). For most accurate readings, the sites were vigorously cleaned with alcohol and gauze pads. EIAH was assumed to have developed when $\mathrm{SaO}_{2}$ decreased by at least $4 \%$ $\left(\Delta \mathrm{SaO}_{2} \leq-4 \%\right)$ from the baseline values [2].

Statistical analyses

Data are reported as means \pm standard deviation (SD). Statistical significance was accepted at $\mathrm{p}<0.05$. The normality of the data was examined by assessing the Shapiro-Wilk test on all measured variables. $\mathrm{SaO}_{2}$ data were not normally distributed and so comparisons between the groups were made using the Whitney-U test. As the other data showed normal distribution, the differences in measures between groups were evaluated by unpaired t-test. To allow a better interpretation of the results, effect sizes were also calculated using Cohen's d [19]. Effect sizes were interpreted as negligible $(\mathrm{d} \geq 0.2)$, small $(0.2 \leq \mathrm{d} \leq 0.5)$, medium $(0.5 \leq \mathrm{d} \leq 0.8)$ or large $(0.8$ $\geq$ d). IBM SPSS 21 software (IBM SPSS Statistics 21 Inc. Chicago, IL) was used for the statistical analysis.

\section{Results}

Table 1 shows the athletes' responses to incremental

Table 1. Results of the incremental treadmill test of the alpine skiers and cross-country skiers.

\begin{tabular}{|c|c|c|c|c|}
\hline Variables & Alpine skiers & Cross country skiers & $\mathbf{p}$ & d \\
\hline $\mathrm{VO}_{2 \max }$ & $52.6 \pm 5.6$ & $66.8 \pm 4.3^{*}$ & 0.001 & 3 \\
\hline $\mathrm{VE}_{\max }(\mathrm{L} / \mathrm{dak})$ & $142.6 \pm 5.1$ & $157.8 \pm 12.4^{*}$ & 0.003 & 1.69 \\
\hline Test time (min) & $7.6 \pm 0.6$ & $10.3 \pm 0.6^{*}$ & 0.001 & 4.74 \\
\hline Speed $_{\max }\left(\mathrm{km} \mathrm{h}^{-1}\right)$ & $14.3 \pm 0.6$ & $17 \pm 0.6^{*}$ & 0.001 & 4.74 \\
\hline $\mathrm{RER}_{\max }$ & $1.2 \pm 0.02$ & $1.1 \pm 0.03 *$ & 0.014 & 4.13 \\
\hline$H R_{\max }\left(\right.$ beat $\left.\min ^{-1}\right)$ & $210 \pm 14.2$ & $207 \pm 11.3$ & 0.57 & 0.25 \\
\hline $\mathrm{VE} / \mathrm{VO}_{2}$ & $40.7 \pm 4.17$ & $38.8 \pm 5$ & 0.36 & 0.44 \\
\hline $\mathrm{VE} / \mathrm{VCO}_{2}$ & $34.5 \pm 2.8$ & $33.6 \pm 3.57$ & 0.53 & 0.3 \\
\hline$\Delta \mathrm{SaO}_{2}(\%)$ & $8.5 \pm 1.7$ & $9.3 \pm 2.8$ & 0.75 & 0.36 \\
\hline
\end{tabular}

Values are mean \pm standard deviation. * Significantly different from alpine skiers. $\mathrm{VO}_{2 \max }=$ maximal oxygen uptake,

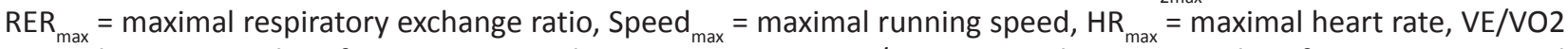
$=$ ventilatory equivalent for $\mathrm{O}_{2}$ at maximal exercise intensity, $\mathrm{VE} / \mathrm{VCO}_{2}=$ ventilatory equivalent for $\mathrm{CO} 2$ at maximal exercise intensity, $\Delta \mathrm{SaO}_{2}=$ difference between rest and maximal exercise values of oxyhemoglobin saturation. 
treadmill exercise tests. $\mathrm{VO}_{2 \max }$, $\mathrm{VE}$, maximal running speed and test time were higher in the cross-country skiers than in the alpine skiers $(p<0.01)$. There were no significant differences between the two groups in $\mathrm{HR}_{\max }, \mathrm{VE} / \mathrm{VO}_{2}$ and $\mathrm{VE} / \mathrm{VCO}_{2}(\mathrm{p}>0.05) . \mathrm{RER}_{\max }$ was higher in alpine skiers than in cross-country skiers $(p<$ 0.05) (Table 1). All the athletes in both groups exhibited EIAH (as defined by $\Delta \mathrm{SaO}_{2} \leq-4 \%$ ) (Figure 1). By comparison there were no differences in resting $\% \mathrm{SaO}_{2}$ values and delta of $\mathrm{SaO}_{2}\left(\Delta \mathrm{SaO}_{2}\right.$, difference between rest and maximal exercise values) between two groups ( $\mathrm{p}>$ 0.05) (Table 1). $\mathrm{SaO}_{2}$ was significantly decreased from $97.5 \pm 0.9 \%$ at rest to $89 \pm 2 \%$ at exhaustion in alpine skiers $(\mathrm{p}<0.001, \mathrm{~d}=5.78)$ and from $97.8 \pm 0.7 \%$ at rest to $88.1 \pm 2.4 \%$ at exhaustion in cross-country skiers ( $\mathrm{p}<$ $0.001, d=5.78)$. No significant differences were observed in the lowest $\% \mathrm{SaO}_{2}$ values occurred at or near maximal exercise intensity between the two groups $(\mathrm{p}>0.05, \mathrm{~d}=$ $0.43)$. EIAH was begun at $71.2 \pm 16.1$ of maximal exercise intensities in cross-country skiers and at $73.8 \pm 12.2 \%$ of maximal exercise intensities in alpine skiers. There were no significant differences in the exercise intensity of began to experience EIAH between two groups ( $p>$ $0.05, d=0.19)$.

\section{Discussion}

EIAH has been reported to more often occur in aerobic trained athletes who have a high $\mathrm{VO}_{2 \max }[2-4$, 6]. We questioned whether EIAH occurs in anaerobic trained athletes who have lower $\mathrm{VO}_{2 \max }$ than aerobic trained athletes. Our results indicated that EIAH occurs in both aerobic and anaerobic trained athletes with varying aerobic capacities. $\mathrm{VO}_{2 \max }, \mathrm{VE}$, maximal running speed and test time were higher in the cross-country skiers than in the alpine skiers, reflecting the cross-country skiers have higher aerobic fitness levels. On the other hand, lowest $\mathrm{SaO}_{2}$ values were not significant difference between in two groups during the incremental exercise test. These findings suggest that although cross-country skiing and alpine skiing require different physical demands and aerobic fitness levels, they may exhibit similar EIAH during the incremental treadmill exercise.

Previous studies have demonstrated that inadequate hyperventilation, pulmonary diffusion limitation and ventilation-perfusion mismatch contributed to EIAH [2, 5, 10, 11]. Most studies have reported that EIAH can occur in only endurance trained individuals with $\mathrm{VO}_{2 \max }$ greater than $60 \mathrm{ml} \mathrm{kg}^{-1} \min ^{-1}[2-4,6,8]$. It has been also demonstrated that training-induced increases in $\mathrm{VO}_{2 \max }$ were accompanied by EIAH [1, 20]. Interesting is the observation that EIAH is not occur in all highly trained athletes. Powers et al. studied the prevalence of EIAH using pulse oximetry in 68 males with varying fitness levels during incremental cycle exercise test. In their study, $52 \%$ of the highly trained subjects developed significant EIAH, whereas none of the untrained or moderately trained subjects demonstrated EIAH [4]. We found that EIAH occurred in all athletes consist of both cross-country skiers and alpine skiers. Anaerobic power is the best predictor of alpine skiing performance [21]. Traditionally, training programs for alpine skiers include anaerobic exercises such as resistance training, speed, change of direction and plyometric training $[22,23]$. On the other hand, cross-country skiing performance relies heavily on the aerobic capacity [24]. Aerobic endurance training has always been the major component of training program in cross-country skiing $[25,26] . \mathrm{SaO}_{2}$ values were not significantly difference between in cross-country skiers and alpine skiers; this may have been due to fact that both groups consisted of the athletes trained regularly. Studies examining EIAH have primarily focused on endurance athletes. However, to our knowledge, there is no previous study examining the occurrence of EIAH in anaerobic trained athletes. Hence, our data represent a rather novel finding that could be of considerable importance for showing the occurrence of EIAH in sports with different physiological demands.

Pulse oximetry has been used extensively the literature to determine EIAH and was deemed a valid and reliable tool to monitor $\% \mathrm{SaO}_{2}$ continuously during exercise [27-
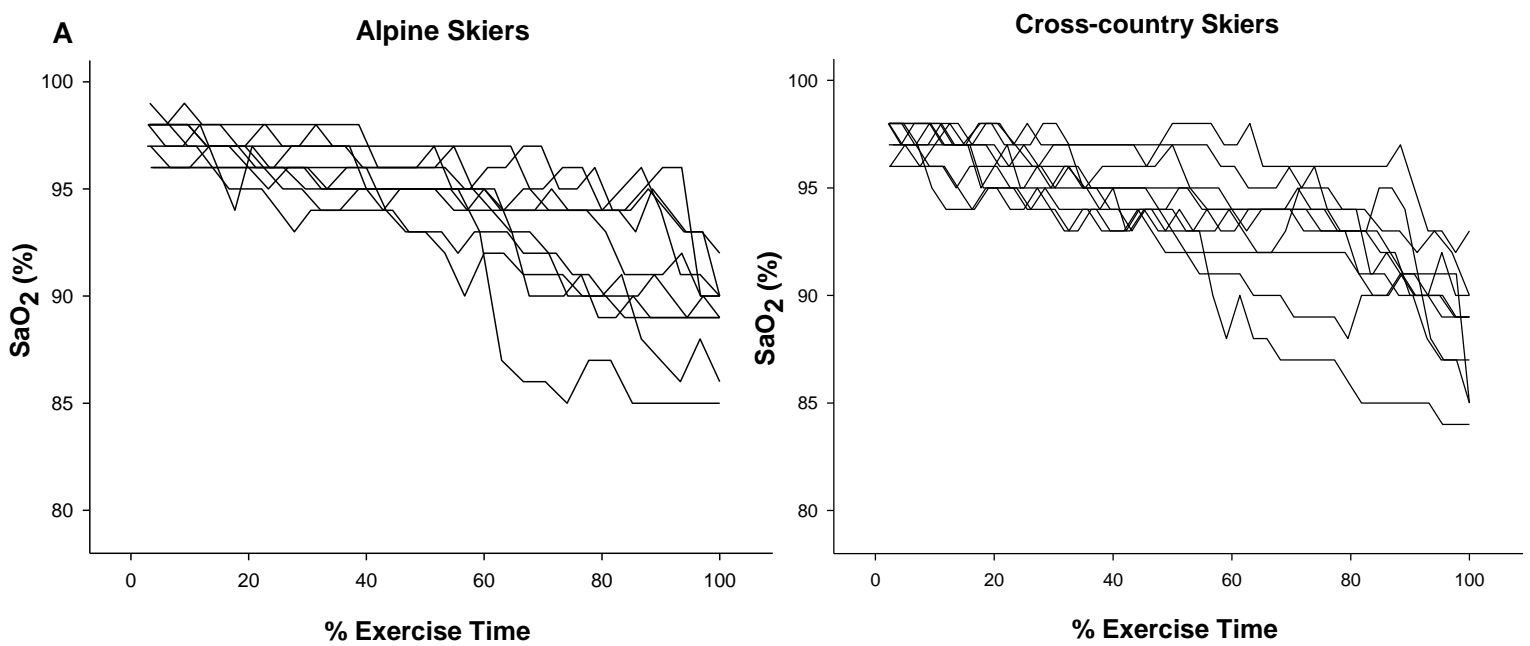

Figure 1. Changes in the percent of oxyhemoglobin saturation $\left(\% \mathrm{SaO}_{2}\right)$ for each subject at different percentages of exercise time during incremental exercise in (A) cross-country skiers and (B) alpine skiers. 
29]. Previous research using pulse oximetry indicated that $\% \mathrm{SaO}_{2}$ values fall in the range between $84 \%$ and $93 \%[6,8,13,30,31]$. Similar changes were observed in our study with the $\% \mathrm{SaO}_{2}$ decreased in the range between $85 \%$ and $92 \%$ during incremental exercise test. The $\% \mathrm{SaO}_{2}$ decreased by approximately $9 \%$ from rest in both groups. Likewise, Alis et al. have reported an $8.25 \%$ decrease in $\mathrm{SaO}_{2}$ from rest during incremental treadmill exercise test [12]. Powers et al shown the difference $\%$ $\mathrm{SaO}_{2}$ between resting and at the $100 \% \mathrm{VO}_{2 \max }$ ranged from $4 \%$ in one subject to $16 \%$ in another [31]. On the other hand, it appear that the mean $\mathrm{SaO}_{2}$ values in our study are lower than have been reported in some previous studies [14-17] yet are similar to those from others [6, 8, 30, 31]. The degree of EIAH is affected the muscle mass engagement in the exercise and the exercise modality [16, 32]. Previous studies have shown a greater drop in the $\mathrm{SaO}_{2}$ at both maximal and sub-maximal exercise during treadmill running compared with ergometer cycling [16, 33]. In the present study, we used incremental treadmill exercise while some studies used incremental exercise on cycle ergometers that have displayed higher $\mathrm{SaO}_{2}$ values than our values. Galy et al., Amann et al., Vogiatzis et al., Gaston et al. and Grataloup et al. using pulse oximetry, have shown reductions in $\% \mathrm{SaO}_{2}$ ranging between $94 \%$ and $91 \%$ during the cycle ergometer test to exhaustion in the endurance athletes [13-17]. Differences of exercise modality and protocol types used may help to explain the differences in $\mathrm{SaO}_{2}$ measured.

During the incremental exercise, EIAH begins to occur even in submaximal exercise in some subjects and usually peaks at or near maximal exercise intensity $[3,18,31]$. EIAH in many trained athletes may begin at moderate intensity workloads due to a widened alveolar-to-arterial oxygen difference and inadequate hyperventilation $[2,3,18]$. Athletes were considered to have developed EIAH when $\mathrm{SaO}_{2}$ decreased by at least 4 $\%\left(\Delta \mathrm{SaO}_{2} \leq-4 \%\right)$ from the baseline values [2]. In this study, we followed the time course of $\mathrm{SaO}_{2}$ from rest to intensities at exhaustion during the incremental treadmill exercise test. EIAH developed at the about 71 and $73 \%$ of maximal exercise intensities for the cross-country skiers and alpine skiers, respectively, and $\mathrm{SaO}_{2}$ decreased over time with increasing intensity. There were no difference in the exercise intensity of began to experience EIAH between two groups. The lowest $\% \mathrm{SaO}_{2}$ occurred at or near maximal exercise intensity in both group with no significant difference between cross-country skiers and alpine skiers. Similar to our findings, Powers et al. shown that $\mathrm{SaO}_{2}$ begins to fall at exercise intensities above $70 \%$ $\mathrm{VO}_{2 \max }$ with the greatest decline occurring at intensities greater than $90 \% \mathrm{VO}_{2 \max }$ [31]. Rice et al. indicated that EIAH occurred at approximately $40 \% \quad \mathrm{VO}_{2 \text { peak }}$, and inadequate hyperventilation is the most likely mechanism at low exercise intensities with a smaller contribution from ventilation-perfusion mismatch [18].

\section{Conclusions}

The results of this study showed that EIAH may occur in endurance athletes with high aerobic capacity as well as anaerobic trained athletes. EIAH showed similar values between cross-country skiers and alpine skiers, which may have been due to both groups of athletes who trained regularly. These findings suggest that well-trained athletes who have different aerobic fitness levels may exhibit similar EIAH during the incremental maximal exercise.

\section{Financing}

No financial support was received for the investigation.

\section{Conflict of interests}

The authors declare that there is no conflict of interests.

\section{References}

1. Rowell LB, Taylor HL, Wang Y, Carlson WS. Saturation of arterial blood with oxygen during maximal exercise. Journal of applied physiology. 1964;19:284-286.

2. Dempsey JA, Wagner PD. Exercise induced arterial hypoxemia. Journal of applied physiology. 1999;87:19972006.

3. Dempsey JA, Hanson PG, Henderson KS. Exercise-induced arterial hypoxaemia in healthy human subjects at sea level. Journal of physiology. 1984;355:161-175.

4. Powers SK, Dodd S, Lawler J, Landry G, Kirtley M, McKnight T, Grinton S. Incidence of exercise induced hypoxemia in elite endurance athletes at sea level. European journal of applied physiology. 1988;58:298-302.

5. Guenette JA, Sheel AW. Exercise-induced arterial hypoxaemia in active young women. Applied physiology, nutrition, and metabolism. 2007;32(6):1263-73.

6. Powers SK, Lawler J, Dempsey JA, Dodd S, Landry G. Effects of incomplete pulmonary gas exchange on $\mathrm{VO}_{2 \max }$. Journal of applied physiology. 1989;66(6):2491-5.

7. Romer LM, Haverkamp HC, Lovering AT, Pegelow DF, Dempsey JA. Effect of exercise-induced arterial hypoxemia on quadriceps muscle fatigue in healthy humans. American journal of physiology. Regulatory, integrative and comparative physiology. 2006;290:R365-R375.

8. Williams JH, Powers SK, Stuart MK. Hemoglobin desaturation in highly trained athletes during heavy exercise. Medicine and science in sports and exercise. 1986;18:16873.

9. Harms CA, McClaran SR, Nickele GA, Pegelow DF, Nelson WB, Dempsey JA. Effect of exercise-induced arterial $\mathrm{O}_{2}$ desaturation on $\mathrm{VO}_{2 \max }$ in women. Medicine and science in sports and exercise. 2000;32(6):1101-8.

10.Hopkins SR, McKenzie DC, Schoene RB, Glenny RW and H. T. Robertson. Pulmonary gas exchange during exercise in athletes. I. Ventilation-perfusion mismatch and diffusion limitation. Journal of applied physiology. 1994;77: 912-917.

11.Prefaut C, Durand F, Mucci P, Caillaud C. Exercise-induced arterial hypoxaemia in athletes: a review. Sports medicine. 2000;30:47-61.

12.Alis R, Sanchis-Gomar F, Ferioli D, La Torre A, Blesa JR, Romagnoli M. Exercise Effects on Erythrocyte Deformability in Exercise-induced Arterial Hypoxemia. International Journal of Sports Medicine. 2015;36(4):286-91.

13.Gaston AF, Durand F, Roca E, Doucende G, Hapkova I, Subirats E. Exercise-induced hypoxaemia developed at sealevel influences responses to exercise at moderate altitude. PLOS ONE. 2016;11(9):e161819. 
14.Amann M, Romer LM, Subudhi AW, Pegelow DF, Dempsey JA. Severity of arterial hypoxaemia affects the relative contributions of peripheral muscle fatigue to exercise performance in healthy humans. Journal of physiology. 2007;581(1):389-403.

15.Grataloup O, Busso T, Castells J, Denis C, Benoit H. Evidence of decrease in peak heart rate in acute hypoxia: effect of exercise-induced arterial hypoxemia. International Journal of Sports Medicine. 2007;28:181-185.

16.Galy O, Le Gallais D, Hue O, Boussana A, Prefaut C. Is Exercise-induced arterial hypoxemia in triathletes dependent on exercise modality?. Internation Journal of Sports Medicine, 2005; 26(9):719-726.

17.Vogiatzis I, Georgiadou O, Giannopoulou I, Koskolou M, Zakynthinos S, Kostikas K, Kosmas E, Wagner H, Peraki E, Koutsoukou A, Koulouris N, Wagner PD, Roussos C. Effects of exercise-induced arterial hypoxaemia and work rate on diaphragmatic fatigue in highly trained endurance athletes. Journal of physiology. 2006; 572(2):539-549.

18. Rice AJ, Scroop GC, Gore CJ, Thornton AT, Chapman MJ, Greville HW, Holmes MD, Scicchitano R. Exerciseinduced hypoxaemia in highly trained cyclists at $40 \%$ peak oxygen uptake. European journal of applied physiology. 1999;79:353-359.

19.Thalheimer W, Cook S. How to calculate effect sizes from published research articles: A simplified methodology. 2002. [cited 2016 January 11]. Available from: http://work learning. com/effect_sizes.htm.

20.Miyachi M, Katayama K: Effects of maximal interval training on arterial oxygen desaturation and ventilation during heavy exercise. Japanese journal of physiology, 1999;49:401-407.

21. White AT, Johnson SC. Physiological comparison of international, national and regional alpine skiers. International Journal of Sports Medicine. 1991;12(4):374378.

22.Hydren JR, Volek JS, Maresh CM, Comstock BA, Kraemer WJ. Review of strength and conditioning for alpine ski racing. Strength \& Conditioning Journal. 2013;35:10-28.

23.Bosco C, Cotelli F, Bonomi R, Mognoni P, Roi GS. Seasonal fluctuations of selected physiological characteristics of elite alpine skiers. European journal of applied physiology and occupational physiology.1994;69:71-74.
24.Staib JL, Im J, Caldwell Z, Rundell KW. Cross-country ski racing performance predicted by aerobic and anaerobic double poling power. Journal of strength and conditioning research. 2000;14(3):282-288.

25.Holmberg HC. The elite cross-country skier provides unique insights into human exercise physiology. Scandinavian Journal of Medicine \& Science in Sports. 2015;25(4):100109.

26.Sandbakk Ø, Holmberg HC. A reappraisal of success factors for olympic cross-country skiing. International journal of sports physiology and performance. 2014;9(1):117-21.

27.Martin D, Powers S, Cicale M, Collop N, Huang D, Criswell D. Validity of pulse oximetry during exercise in elite endurance athletes. Journal of applied physiology. 1992; 72: 455-458.

28.Powers SK, Dodd S, Freeman J, Ayers GD, Samson H, Mcknight T. Accuracy of pulse oximetry to estimate $\mathrm{HbO}_{2}$ fraction of total $\mathrm{Hb}$ during exercise. Journal of applied physiology. 1989;67:300-304.

29.Mollard P, Bourdillon N, Letournel M, Herman H, Gibert S, Pichon A, et al. Validity of arterialized earlobe blood gases at rest and exercise in normoxia and hypoxia. Respiratory Physiology Neurobiology. 2010; 172: 179-183.

30.Brown DD, Knowlton RG, Sanjabi PB, Szurgot BT. Reexamination of the incidence of exercise-induced hypoxaemia in highly trained subjects. British Journal Sports Medicine. 1993; 27(3):167-70.

31.Powers SK, Dodd S, Woodyard J, Beadle RE, Church G. Haemoglobin saturation during incremental arm and leg exercise. British Journal Sports Medicine. 1984; 18: 212-16.

32.Rasmussen J, Hanel B, Diamant B, Secher NH. Muscle mass effect on arterial desaturation after maximal exercise. Medicine and science in sports and exercise. 1991;23:13491352.

33.Rice AJ, Scroop GC, Thornton AT, McNaughton NS, Rogers KJ, Chapman MJ, Greville HW, Scicchitano R, Gore CJ. Arterial hypoxaemia in endurance athletes is greater during running than cycling. Respiratory Physiology. 2000:123: 235-246.

\section{Information about the authors:}

Selcen Korkmaz Eryılmaz (Corresponding author); http://orcid.org/0000-0002-3680-3580; selcen_korkmaz@yahoo.com; School of Physical Education and Sports, Cukurova University; 01330 Balcali, Saricam. Adana. Turkey.

Metin Polat; http://orcid.org/0000-0001-7299-0531; polat.metin@gmail.com; School of Physical Education and Sports, Erciyes University; Erciyes University T Block, Kayseri, Turkey.

Cite this article as: Selcen Korkmaz Eryılmaz, Metin Polat. Exercise-induced arterial hypoxemia in aerobic and anaerobic trained athletes during incremental exercise. Physical education of students, 2018;22(2):99-103. doi:10.15561/20755279.2018.0207

The electronic version of this article is the complete one and can be found online at: http:/www.sportedu.org.ua/index.php/PES/issue/archive

This is an Open Access article distributed under the terms of the Creative Commons Attribution License, which permits unrestricted use, distribution, and reproduction in any medium, provided the original work is properly cited (http://creativecommons.org/licenses/by/4.0/deed.en).

Received: 29.03 .2018

Accepted: 17.04.2018; Published: 27.04.2018 